\title{
Markov-modeling for the administration of platinum analogues and paclitaxel as first-line chemotherapy as well as topotecan and liposomal doxorubicin as second-line chemotherapy with epithelial ovarian carcinoma
}

\author{
M. Fedders $\cdot$ M. Hartmann $\cdot$ A. Schneider $\cdot$ R. Kath $\cdot$ \\ O. Camara $\cdot$ H. Oelschläger
}

Published online: 25 September 2007

(C) Springer-Verlag 2007

Erratum to: J Cancer Res Clin Oncol (2007) 133:619-625

DOI 10.1007/s00432-007-0210-4

The original version of this article unfortunately contained a mistake. The order of the authors was incorrect. The correct order of authors is as follows:

Fedders M, Hartmann M, Schneider A, Kath R, Camara O, Oelschläger $\mathrm{H}$.

The online version of the original article can be found under doi: 10.1007/s00432-007-0210-4.

M. Fedders $(\bowtie)$

Duisburg Hospital, Zu den Rehwiesen 9,

47055 Duisburg, Germany

e-mail: maike.fedders@uni-duisburg-essen.de

M. Hartmann

FSU Hospital Pharmacy, Erlanger Allee 101,

07743 Jena, Germany

A. Schneider

Hospital for Gynecology and Interdisciplinary Breast Center,

Charité Campus Mitte, Charitéplatz 1, 10117 Berlin, Germany

R. Kath

Clinic for Hematology and Oncology, Medical Clinic I,

Hospitals Essen Nord-West, Hülsmannstrasse 6,

45355 Essen, Germany

O. Camara

Hospital for Gynecology FSU Jena,

Bachstrasse 18, 07740 Jena, Germany

H. Oelschläger

Institute for Pharmacy FSU Jena,

Semmelweissstrasse 10, 07743 Jena, Germany 